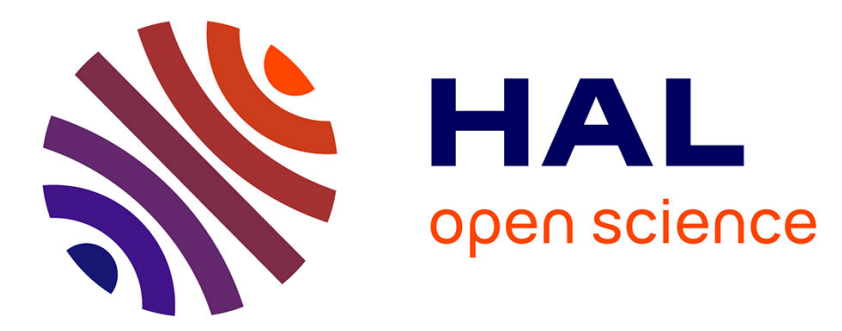

\title{
Electric field sensing: What is brought by duality from flux gates?
}

Didier Robbes, Corentin Jorel, E. Olivier, Laurence Méchin, Sylvain Lebargy, Rachid Bouregba, Gilles Poullain, C. Cibert

\section{- To cite this version:}

Didier Robbes, Corentin Jorel, E. Olivier, Laurence Méchin, Sylvain Lebargy, et al.. Electric field sensing: What is brought by duality from flux gates?. SENSORS, 2013 IEEE, 2013, pp.1-4. 10.1109/ICSENS.2013.6688412 . hal-01064152

\section{HAL Id: hal-01064152 https://hal.science/hal-01064152}

Submitted on 15 Sep 2014

HAL is a multi-disciplinary open access archive for the deposit and dissemination of scientific research documents, whether they are published or not. The documents may come from teaching and research institutions in France or abroad, or from public or private research centers.
L'archive ouverte pluridisciplinaire HAL, est destinée au dépôt et à la diffusion de documents scientifiques de niveau recherche, publiés ou non, émanant des établissements d'enseignement et de recherche français ou étrangers, des laboratoires publics ou privés. 


\section{Electric Field Sensing: what is brought by duality from Flux Gates?}

\author{
D. Robbes, C. Jorel, E. Olivier, L. Méchin, S. Lebargy \\ GREYC UMR 6072, \\ UNICAEN \\ Caen, France \\ didier.robbes@unicaen.fr
}

\author{
R. Bouregba, G. Poullain, C. Cibert \\ CRISMAT/CNRT-Matériaux \\ ENSICAEN \\ Caen, France
}

\begin{abstract}
Ways to sense electric field using PZT capacitors are investigated. Duality rules a priori apply to material physics, linking polarization to magnetization properties, i.e. $D(E)-B(H)$ curves, but no real electrical flux gate or charge gate does exist which would be the dual of common flux gate magnetometer. The Landau - Khalatnikov equations are applied to ferroelectric materials subjected to both a DC and AC pumping signal. They are solved to get model of the PZT capacitors dynamics. They are experimentally investigated using the Sawyer Tower method. A second harmonic detection is a way to extract the DC excitation.
\end{abstract}

\section{INTRODUCTION}

Using theMany measuring principles are currently used to manufacture various magnetic sensors, among which the Magnetic Flux Gates (MFG) are considered as reference sensors for room temperature magnetic field $\mathrm{H}$ (or flux density B). Besides, the conjugated physical quantity of $\mathrm{H}$, i.e. the electrical field $\mathrm{E}$, is far from being easily measured, especially if $\mathrm{E}$ include a DC component. There are many origins to the quasi lack of E field measuring system. As discussed here, they are one of our motivations. A better understanding of the deep reasons of this unbalance between $\mathrm{E}$ and $\mathrm{H}$ fields measuring processes, while they are so strongly linked, should then help to get new E field sensors. A methodology based on duality rules applied both to the physical quantities of the used measuring principles as well as to their electronic conditioning units is used. Because search coils, built around magnetic cores, are the basic component of MFG, then search capacitors, built around a ferroelectric (FE) body, should be the basic component of the MFG dual. Such a concept of "Electrical Charges Gate" (ECG) is not similar to the one proposed earlier [1], that was limited to a functional duality, expressed only at the level of Thévenin-Norton representations. Our contribution starts with a modified concept of the capacitive electrometer. Just based on the dual of the Lenz's law, the measuring principle of search coil magnetometers, we call them search capacitors electrometer. Introducing a FE material $\mathrm{Pb}(\mathrm{Zr0}$.6Ti0.4)O3 (PZT) [2] in the previous search capacitor allows us to investigate, both numerically and experimentally, the main features of their signal dynamics when subjected to a voltage having $\mathrm{AC}$ and DC components. Understanding such a signals is the necessary step to design ECG using dual analogy with MFG.

The paper is ordered as follow: section II details our motivation and introduces section III, in which we go back to fundamental electric and magnetic induction laws with a balanced formal presentation and finally obtain the search capacitor electrometer. Section IV and V are devoted to PZT capacitors measurements and dynamical modeling. The last section discusses and proposes openings to the present work.

\section{Motivations}

At the very beginning of our work was a questioning in the domain of science learning at the college level: why is it so easy to apply and measure magnetic fields, whereas the same is not true for the electric ones, especially when DC values are involved? That question concerns most of physics teachers in charge of lectures on electricity, electromagnetism and vector's algebra fundamentals, especially when they want to illustrates these fundamentals with experiments. Such a questioning was at the center of [3], a paper dedicated to about 15 pedagogical experiments around Maxwell equations. That questioning can also be appreciated after reading [4]. An equivalent paper devoted to electrical induction laws is still missing : we were unable to find one in literature excepted in the last chapter of [5]. In the framework of an industrial development, a directional, wide bandwidth and wide dynamic range capacitive electrometer [6] was built. Besides science learning many other applications exist : electrostatic discharge (ESD) sources localization, high field, systems control and monitoring, non destructive evaluation (NDE) of insulating and composite materials, non invasive medical instruments (EEG \& ECG), electromagnetic interferences (EMI), storms and lightning's activity, etc. Most of these applications would benefit from a low noise instrument working in the DC mode and with an extended bandwidth and dynamic range. 


\section{BACK TO FUNDAMENTALS OF THE SEARCH CAPACITOR ELECTROMETER}

One key missing point when developing electrometers or charge amplifiers is a Norton circuit accounting for the electrical influence of an external $\mathbf{E}$ field upon free charges of highly conductive metallic electrodes. The Thévenin equivalent circuit of magnetic capture using a search coil is associated to the mesh equation:

$$
e+L \frac{d i}{d t}+R i+\frac{d \phi_{e x t}}{d t}=0
$$

where $\phi_{e x t}=S_{c a p} B_{\text {ext }}$ is the link to the field measured from the voltage drop $e$ across the coil terminals, once the capture area $S_{c a p}$ is known. The circuit current $i$ is set to 0 if a high impedance amplifier is used. The dual equation of $\mathrm{Eq}(1)$ is easily written as the node equation of Kirshhoff's circuit laws:

$$
i+C \frac{d v}{d t}+G v+\frac{d Q_{e x t}}{d t}=0
$$

but the physical meaning of the variables in (2), especially $Q_{e x t}$ is still unclear, even to men of the Art. Chapter IV of [5] proposes a detailed explanation of this meaning, on which we focus here with the help of Fig. 1. It shows a conducting ring together with its physical dual. The former is the basic search coil, with a slot to generate a voltage drop caused by magnetic induction variations. The latter is a pair of conducting discs with a short between them. The electric influence phenomena creates a current $-d Q_{\text {ext }} / d t$ where $Q_{\text {ext }}=S_{\text {cap }} D_{\text {ext }}$ is associated to the flux of the classical electrical induction field through a surface $S_{\text {cap }}$. The latter can be defined from a contour line [5]. The dual of the slotted ring looks like a conducting Yo-Yo, the bulky discs of which are two electrical charges reservoirs. The short allows charges exchange between them. Subjected to an external $\mathbf{E}$ field drive, the surface charge density adapt itself to produce the induced field that cancels the external one both inside the bulky conducting electrodes and in the thin dielectric that surrounds the short between the electrodes. The amplifier to measure that short-circuit current should be a transimpedance amplifier that exhibits an input admittance much higher than those associated to $\mathrm{C}$ and $\mathrm{G}$ introduced in $\mathrm{Eq}$ (2) so that they can be neglected in the operating frequency range. Once the short is connected to the high admittance input amplifier (using properly guarded cables), that $\mathbf{E}$ field capturing device no longer appears as a Yo-Yo, but returns to the basic plan capacitor, justifying the search capacitor's name. Introducing a dielectric material in between the electrode pair, especially those exhibiting non linear properties like PZT's, then benefits from the Yo-Yo picture (except the spatial shift of the short): the externally induced charges exchange between the bulky Yo-Yo electrodes is modulated, thanks to
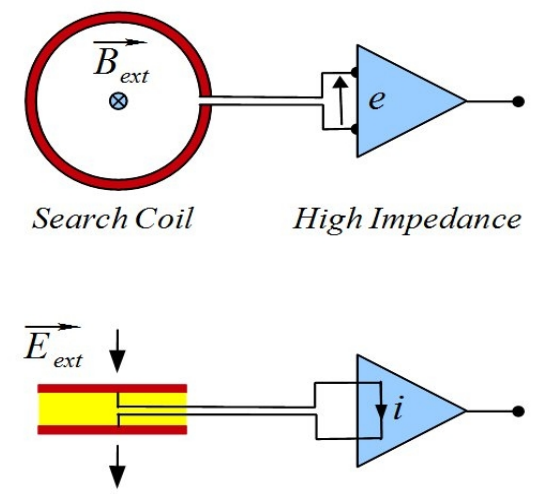

Search Capacitor High Admittance

Figure 1. Idealized search coil magnetometer and sear capacitor electrometer. The sensors physical outputs is conveyed by a line to the high impedance or high admittance inputs amplifiers.

the saturation process that is included in these non linear materials. That picture highlights a mechanism for the proposed Electrical Charge Gate, the dual device of the MFG. The necessary step to get ECG is the accurate modeling of the signal dynamics in PZT based capacitors. A way is proposed in the next section.

\section{PZT CAPACITRORS DYNAMICS}

To understand which features of the dynamics are needed, let us remind the measuring principle of MFGs. In Fig. 2a, a typical magnetization curve $\mathbf{B}(\mathbf{H})$ of a soft magnetic material is plotted, together with a pumping AC signal. Clearly, the DC value, which is just superimposed to the $\mathrm{AC}$ one at the input, is mixed with the $\mathrm{AC}$ in the induced signal, the harmonics content of which being then linked to the DC value.

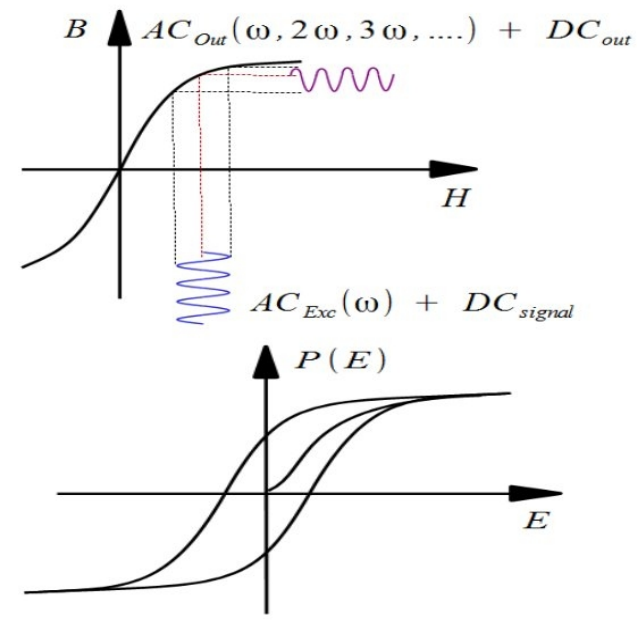

Figure 2. Idealized search coil magnetometer and sear capacitor electrometer. The sensors physical outputs is conveyed by a line to the high impedance or high admittance inputs amplifiers. 


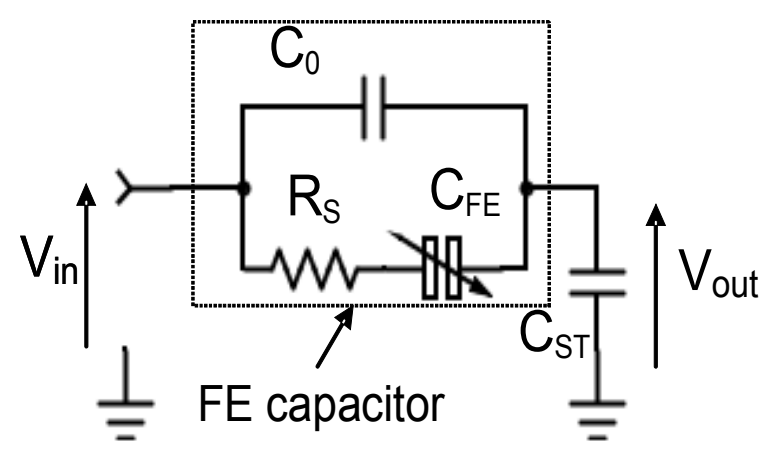

Figure 3. Sawyer-Tower circuit including the ferroelectric capacitor (FE) equivalent circuit. $\mathrm{C}_{0}$ represents the vaccum capacitor linked to $\varepsilon_{0}$, Rs the dissipation component and $\mathrm{C}_{\mathrm{FE}}$, the ferroelectric contribution. $\mathrm{C}_{\mathrm{ST}}=22 \mathrm{nF}$ was used as the ST (Sawyer-Tower) capacitor to measure the charge on the FE capacitor $\mathrm{C}_{\mathrm{FE}}$

This modulation principle is used in MFG to be sensitive to DC fields in magnetic cores coils. That measuring principle is thought to be usable for DC electric field as well, using the polarization curve $\mathbf{P}(\mathbf{E})$ (ex. Fig. 2), although the modulation should be modified, due to hysteresis behavior of the $\mathbf{P}(\mathbf{E})$ in FE. Lead zirconate titanate or PZTis a perovskite material that has been extensively investigated since [7]. For this work $\mathrm{Pb}\left(\mathrm{Zr}_{0.6} \mathrm{Ti}_{0.4}\right) \mathrm{O}_{3}$ thin film capacitors were prepared on $\mathrm{Pt} / \mathrm{TiO}_{2} / \mathrm{SiO}_{2}$ buffered $\mathrm{Si}$ substrates using a multitarget sputtering system. Detailed description of the preparation and characterization of these films are in [8], but they are subjected to fatigue degradations [9]. New fabrication routes are possible using oxide $\mathrm{SrRuO}_{3}$ conductive electrodes to overcome that critical issue for sensors operations [10].

$250 \mu \mathrm{m} \times 250 \mu \mathrm{m}$ Pt top electrodes and $180 \mathrm{~nm}$ thick PZT films were used to study the ferroelectric polarization dynamics and analyze different ways of extracting the DC field from the measurements. The equivalent circuit (Fig. 3) proposed in [11] and [12] was used as the LandauKhalatnikov dynamical ferroelectric model: to separate the geometric contribution of the equivalent vacuum capacitor parallel, $\mathrm{C}_{0}$ is used. Computed polarization loops were obtained using MATLAB Simulink, as presented in [13]. In order to advance towards actual sensors circuit design, the modeling was then transferred to SPICE. The phenomenological model developed by Miller [14], which uses two hyperbolic tangent branches and an intrinsic multiparameters fitting optimization, was tested but, as it does not use or give any dynamical information, it is not of practical interest for our purpose. The classical Sawyer-Tower test circuit (Fig. 3) [15] was used to measure the $\mathrm{D}(\mathrm{E})$ polarization loops. Note that $\mathrm{P}(\mathrm{E})$ is plotted as the $\varepsilon_{0} \mathrm{E}$ contribution is negligible in high permittivity dielectric such as PZT. P represents the total polarization of the ferroelectric film. It includes that part of the polarization related to the polarizability of the material assumed linear, and the

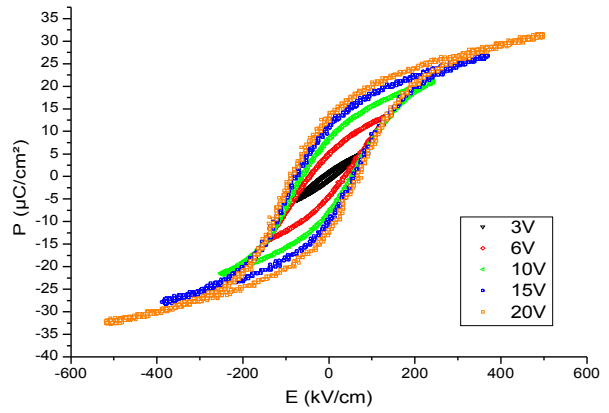

Figure 4. Set of polarization loops obtained with increasing driving amplitude on one FE capacitor.

ferroelectric part of the polarization related to the switching domains, essentially non linear.The following expressions (3) and (4) are used for plotting the hysteresis loops:

$$
\begin{gathered}
\mathrm{E}(\mathrm{t})=\frac{\mathrm{V}_{\text {in }}(\mathrm{t})-\mathrm{V}_{\text {out }}(\mathrm{t})}{\mathrm{t}_{\mathrm{PZT}}} \\
\mathrm{D}(\mathrm{t})=\mathrm{P}(\mathrm{t})=\frac{\mathrm{Q}_{\mathrm{FE}}}{\mathrm{A}_{\mathrm{FE}}}=\frac{\mathrm{Q}_{\mathrm{ST}}}{\mathrm{A}_{\mathrm{FE}}}=\frac{\mathrm{C}_{\mathrm{ST}} \times \mathrm{V}_{\text {out }}}{\mathrm{A}_{\mathrm{FE}}},
\end{gathered}
$$

where $t_{\mathrm{PZT}}$ is the PZT film thickness $(180 \mathrm{~nm}), \mathrm{Q}_{\mathrm{FE}}$ and $\mathrm{Q}_{\mathrm{ST}}$ the charge stored by the FE and ST capacitors and $\mathrm{A}_{\mathrm{FE}}$, the FE capacitor area $(250 \mu \mathrm{m} \times 250 \mu \mathrm{m})$. $\mathrm{Q}_{\mathrm{FE}}$ and $\mathrm{Q}_{\mathrm{ST}}$ are considered equal since we neglect all the conduction currents. The obtained polarization loops showed the usual behavior with increasing $V_{\text {in }}$ sine wave amplitude Fig. 4 [16]. From the high field part of these curves, we are able to extract the spontaneous polarization and the contribution of the linear permittivity $\varepsilon_{\mathrm{rLin}}$.

Dynamic modeling, as proposed in [12], has been very easily implemented using the graphical programming language Simulink of the MATLAB environment [13]. An implementation using SPICE is now carried out, producing a FE capacitor dipole. Both dynamic simulations results are shown in Fig. 5, which surrounds the experimental ones. It is worth to note that it is not a mathematical fitting with optimized parameters like in the Miller [14] type of modeling. Here, two physical constants are extracted from the experimental loop: the capacitance at $\mathrm{E}=0\left(\mathrm{C}_{\mathrm{E}=0}\right.$ from the slope at $E=0$ ) and the resistance $R_{S}$ from the dissipative area of the hysteresis. From there, the two constants of the dimensionless equation [11] are calculated and implemented in the model. The Curves presented in Fig. 5 are directly computed from the 


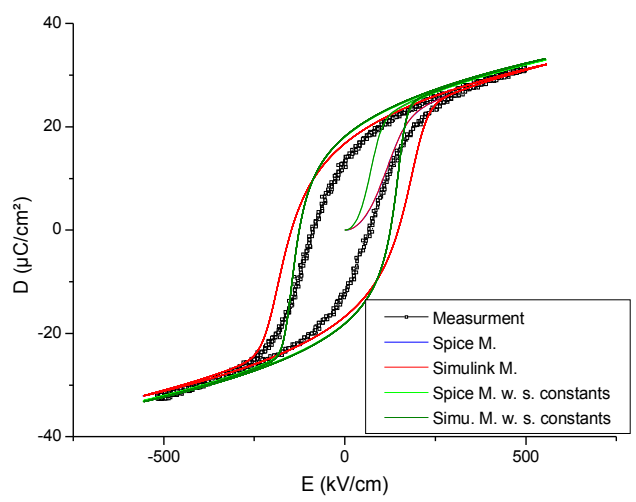

Figure 5. Measured and simulated hysteresis loop at $500 \mathrm{~Hz}$ and with 10

$\mathrm{V}_{\mathrm{PP}}$ sin wave excitation. Green simulated curves are obtained with a constants arbitrary shift.

chosen $\mathrm{R}_{\mathrm{S}}$ and $\mathrm{C}_{\mathrm{E}=0}$ values. Nevertheless, these two quantities extracted from the data did not allow a satisfying fit with experimental data. As a comparison, another arbitrary set of these two values is shown Fig. 5. $\mathrm{R}_{\mathrm{S}}$ and $\mathrm{C}_{\mathrm{E}=0}$ were changed from respectively $8.5 \mathrm{k} \Omega$ and $6.5 \mathrm{nF}$ to $5.4 \mathrm{k} \Omega$ and $3.1 \mathrm{nF}$. Apart from a slightly better fit of the effective coercive field and loop surface, an a posteriori tailoring of the two parameters does not enhance the match between simulated and measured loops. In fact, that agreement is satisfactory, and, most important, simulated and measured temporal responses are very close to each other.

\section{Electrical DC Field Extraction and conclusion}

As presented earlier on time plots of the voltage $\mathrm{V}_{\text {out }}$ (Fig. 3 ) and on its spectrum [13], the second harmonic component of $V_{\text {out }}$ is similar to that used in MFG. Here we present lock-in measurements of $\mathrm{V}_{\text {out }}$ and simulation performed with $\mathrm{V}_{\text {in }}=10$

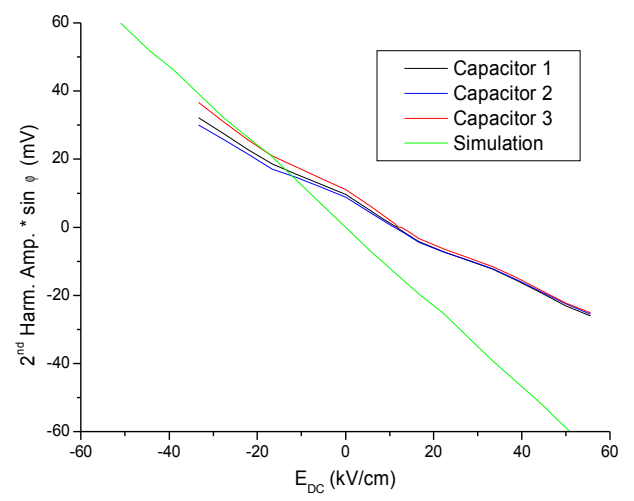

Figure 6. $2^{\text {nd }}$ harmonic amplitude vs. external applied static field E. $\varphi$ is the phase difference with the $\mathrm{AC}$ applied $\mathrm{V}_{\text {in }}$.
$V_{\mathrm{PP}}$ at $500 \mathrm{~Hz}$. They are presented Fig 6. in which the same two constants extracted from the experimental data are used for the simulation. The conversion coefficient between the DC input field and the $\mathrm{AC}$ voltage output is about $0.7 \mathrm{mV} / \mathrm{kVcm}^{-1}$ for experimental plots and about $1.2 \mathrm{mV} / \mathrm{kVcm}^{-1}$ for the simulated ones using the Landau- Khalatnikov modeling. At this level, we consider this disagreement not so large, associated to the modeled characteristics that are less rounded than the experimental ones. Most of the behavior of the needed parametric signal transfer are clearly obtained, they will help the design of the Electric Charge Gate to be investigated in a next step, both with regards to the input coupling and to other outputs conditioning.

\section{REFERENCES}

[1] Kaplan B. Z., Suissa U.,'Duality of the electric covering fieldmill and the flux gate magnetometer", IEEE Transactions on Magnetics, vol. 34, issue 4, Jul 1998, pp. 2306-2315.

[2] R. Bouregba and G. Poullain, Ferroelectrics, vol. 274, 2002, pp. $165-$ 181.

[3] D. Robbes, T. Salley, F. Dijoux, B. Dufay, G. Allègre, M.Timofeeva, S. Morteau, "Autour des équations de Maxwell, EDP Sciences, J3e2a Vol. 9, 12p, 2012.

[4] M. Timofeeva, G. Allègre, S. Flament and D. Robbes, “ Des lois de l'induction aux théorèmes de Thevenin et de Norton", EDP Sciences, J3e2a Vol. 9, 6p, 2010.

[5] M. Timofeeva, Ph. D Thesis, University of Caen Basse Normandy, 2012.

[6] Didier Robbes, "Physical Quantity Measuring Unit and Device for Measuring a Voltage and an Electric Field", European Patent Application No. 09290213.9, date 20.3.2009.

[7] J. Scott and C. P. de Araujo, Sciences 246, 1989, pp. 1400-1405.

[8] B. Vilquin, R. Bouregba, G. Poullain, M. Hervieu, and H. Murray, European Physical Journal - Applied Physics, vol. 15, issue 3, 2001, pp. 153-165.

[9] R. Ramesh, W.K. Chan, B.Wilkens, H. Gilchrist, T. Sands, J.M. Tarascon, V.G. Keramidas, D.K. Fork, J. Lee, and A. Safari, Appl. Phys. Lett. 61, 1991, pp. 1537.

[10] Corentin Jorel, Héloïse Colder, Alice Galdi, Laurence Méchin, "Epitaxial PZT thin films on YSZ-buffered $\mathrm{Si}$ (001) substrates for piezoelectric MEMS or NEMS applications", IOP Conf. Ser.: Mater. Sci. Eng. 41012012 (2012).

[11] S. Sivasubramanian, A. Widom, Y. Srivastava, "Physical Kinetics of Ferroelectric Hysteresis", Ferroelectrics, vol. 300, 2004, pp. 43-55.

[12] S. Sivasubramanian, A. Widom, Y. Srivastava, IEEE Trans. Ultrason. Ferroelectr. Freq. Control., 50(8), 2003, pp. 950-957.

[13] Didier Robbes, A. Théogène, S. Lebargy, C. Jorel, L. Méchin, R. Bouregba, G. Poullain, C. Cibert, "PZT thin films capacitors : a way to sense Electric field ?", Mama trend conference, oral contribution, May 2013.

[14] S. L. Miller, R. D. Nasby, J. R. Schwank, M. S. Rodgers, and P. V. Dressendorfer, "Device modeling of ferroelectric capacitors", J. Appl. Phys. 68(12), 1990, pp. 6463-6471.

[15] C. B. Sawyer and C. H. Tower, "Rochelle salt as dielectric", Phys. Rev., vol. 35, 1930, pp. 269-273.

[16] D. J. Wouters , G. J. Norga, and H. E. Maes, "ultra-thin PZT films for low-voltage ferroelectric non volatile memories",Mater. Res. Soc. Symp. Proc., vol. 541, 1999, pp 381-391. 